\title{
REFLECTION
}

\section{Family Physicians Leaving Their Clinic- The Balint Group as an Opportunity to Say Good-bye}

\author{
Yuval Shorer, $M D^{1}$ \\ Aya Biderman, $M D^{2}$ \\ Ayelet Levy, $M D^{2}$ \\ Stanley Rabin, $P b D^{1}$ \\ Abaron Karni, $M D^{3}$ \\ Benyamin Maoz, MD, PbD \\ Andre Matalon, $M D^{4}$ \\ 'Soroka University Medical Center, Psy- \\ chiatric Department, Faculty of Health Sci- \\ ences, Ben Gurion University of the Negev, \\ Beer Sheva, Israel \\ ${ }^{2}$ Clalit Health Services Southern District, \\ Beer Sheva, Family Medicine Department,
} Faculty of Health Sciences, Ben Gurion University of the Negev, Israel

${ }^{3}$ Clalit Health Services, Jerusalem District, Israel

${ }^{4}$ Clalit Health Services, Dan-Petach Tikva District and the Family Medicine Department, Sackler School of Medicine, Tel Aviv University, Israel

AC Annals Journal Club selection; see inside back cover or http://www. annfammed.org/site/AJC/.

Conflicts of interest: authors report none.

\section{CORRESPONDING AUTHOR}

Yuval Shorer, MD

Psychiatric Department

Soroka University Medical Center

Clalit Health Services

Faculty of Health Sciences

Ben Gurion University of the Negev

Beer Sheva Israel

yuvalshorer@gmail.com

yuvalsh2@clalit.org.il

\begin{abstract}
The cornerstone of family medicine is the belief in both the continuity and availability of care. These beliefs are challenged when a doctor leaves his or her clinic because of personal reasons. In the example described in this article, the involvement of colleagues in a Balint group led a doctor to a flash insight into her conflicting feelings related to leaving her clinic. The group process helped her to prepare and deal with her own feelings and needs, as well as those of her patients and staff. Balint groups are a secure place to explore and gain insight into the emotional aspects of attachment and separation of physicians from their patients.
\end{abstract}

Ann Fam Med 2011;9:549-551. doi:10.1370/afm.1298.

$\mathrm{t}$ was summer, noontime, a pause in time, an island of rest in the middle of a hectic working day for 8 family physicians preparing to meet with their regular Balint group.

A Balint group ${ }^{1}$ is a discussion group of peers, doctors, and other health professionals with whom it is possible and appropriate to bring up issues and problems that arise from the interaction between the doctor and patient and the patient's family. A Balint group is neither group psychotherapy nor a staff meeting. It is a closed group of 8 to 15 participants, led by 1 or 2 leaders (in this case, a physician and a mental health professional) which meets once every 3 to 4 weeks. It is unique in providing an accepting and nonjudgmental atmosphere to its members.

Among the participants in the group is Dr G, who comes from a busy rural clinic in an area of new immigrants near the border where regular security skirmishes take place. Dr S, himself a new immigrant, treats patients in an urban clinic caring for immigrants from Russia, Ethiopia, and South America. Dr A, a mother of 3 young children, works in a clinic on a moshav (rural settlement), where there are very strong community ties. She feels that the practice in which she works is very close knit, like a family. Sometimes she finds that she has to carefully maneuver between home and family demands and work pressures.

This Balint group has met for 2 years, and a few minutes of friendly chatting and the usual ritual of the group leaders' opening question-"Who has a follow-up report?" (of previous cases)—connects and absorbs everyone to this special setting. Next, the leader asks, "Who has a new case?" Dr A, our moshav doctor says, "Well it's not urgent. ... I'm not sure if it's a problem at all? But if no one else has a case, I have one." She continues:

In the small moshav where I am the physician, a family has lost an 18-year-old son in a car accident. A real tragedy! The family doesn't usually come to see me, no special problems. They finished the shivah (7 days of mourning, according to the Jewish religion) 2 weeks ago. I didn't visit them. I am not sure what to do. 
This is the place in the group for informative questions about the patients.

They are 5 in the family, the father (60 years), a farmer, the mother (55 years), a social worker, and there is a 25 -year-old son and a 22-year-old daughter. They have no special physical problems; the father had back problems, but he almost never comes for a checkup. If I invite them in, what will be the reason? If the loss is the issue, is this my task as a doctor to open this issue up?

The group defines these questions as central. Dr A agrees hesitantly and takes her seat. The group discussion begins with a silence of uneasiness and heaviness, which is quickly filled with a somewhat intellectual discussion of similar cases of grief work with patients and families. The group ponders: Dr A generally has a positive approach toward psychosocial interventions such as this one. So what's the real question? These moments of confusion are always a challenge to leaders and participants in a Balint group, calling for emotional clarification. ${ }^{2}$

The leader states, "I feel that we are a little confused or missing some other issue." There is a general spirit of agreement as the leader continues:

I assume that most of you are aware that Dr A is going to be leaving the practice for a few years, because of her husband's temporary relocation abroad. What do you think? Maybe her question about the family in grief is connected to her forthcoming leaving the practice?

Silence.... The eyes are turned to Dr A, sitting a little outside the circle, but now feeling very moved and very close to the group members. She is invited to rejoin the group. Dr A, embarrassed:

Wow! It's amazing! I almost "skipped" the separation process. I have been totally immersed in the work itself, working as though there is no tomorrow, with patients, home visits, staff meetings, daily duties at home with my own 3 small children, you know...."

The subject of separation, a universal human experience, usually arises in Balint groups in the context of a patient transferring to another doctor or, of course, in the instance of a physician's retirement or a patient's death. A physician leaving the practice because of personal reasons may challenge the importance of continuity of care and the fantasy of being constantly available to patients and their families. ${ }^{3-5}$

As participants shared experiences of separation and death encountered in their practices, Dr A gained insight into the impact of her upcoming separation.

"I've now got it! How the separation is affecting me!" She had a flash insight, ${ }^{6,7}$ a moment of sudden intellectual and emotional understanding of how she had ignored her upcoming move from her practice and the group. She told the group that she is leaving the practice for a few years, because of her husband's temporary reallocation abroad. She explained,

I waited for this opportunity. You know, despite having years of great satisfaction in work in the moshav clinics with the patients and families and the dedicated staff, I already felt tired and burnt out at work. And especially the combination of work and raising my 3 small children, it was tough!

A group participant wonders, "I understand and ask: who helps you, Dr A?" and the leader continues, "Now we realize the real question that we were missing from the beginning: how to suggest help for the helper?"

The group discussed the complex types of separation from patients and families caused by death, leaving clinics, and moving for other reasons. Dr A became more aware of her unconscious emotions about leaving: her overactivity was an escape and defense from feeling pain and sorrow.

There was a feeling of disquiet in the group, an emotional reaction to Dr A's conflict, which the group discussed. Every departure is accompanied by contradictory feelings - on the one hand sadness, while on the other, feelings of release, growth, and challenge. In addition, the participants acknowledged that increased activity around a departure stems, among other reasons, from the difficulty of connecting to the inner sadness and pain associated with leaving. Acknowledging these emotions clarifies the need to prepare for departure in a conscious and operational way, looking at the doctor's personal issues as well as the reactions of the patients separating from their physician. Awareness of all the conflicting feelings significantly eases separation.

The group involvement helped Dr A become aware of the need to plan her departure. It also allowed her to elaborate on the meaning of leaving and its implications for the staff with whom she worked and for her patients. She shared the positive feelings that arose from her expectations of moving, yet other issues had to be faced: "What will happen after I return?" and "Will the relocation change my attitude towards my profession and place of work?"

In subsequent meetings Dr A shared with her colleagues the ramifications of the meeting for her:

I didn't think that I needed to work out the separation emotionally, since my leaving work was for happy reasons, and was positively desired. During the process, I learned that my interactions with patients and fellow team members were significant and precious to me, and it was not easy to be leaving all of that.

In addition she told of reactions from staff members and patients to her leaving. Some patients were 
astonished, some angry, and some sad, whereas others seemed to ignore it altogether.

As a result of the Balint meeting, the doctor planned her departure from the clinic. The process included the participation of nurses, circulation of a letter to her patients, a coordinating conversation with the doctor who was to replace her, and direct invitations of certain, selected, patients to come in for a personal farewell. The planned departure benefitted Dr A's replacement, who was also a member of the Balint group. Through the group discussion, this doctor also thought of ways to separate from her own patients so she could take up this new position.

Elder, in his article, "The GP Surgery as a Secure Base: Patterns of Attachment in Primary Care," ${ }^{18}$ argues that if professionals feel secure and respected within the practice, then the practice itself is more likely to function as a secure base for its patients. In this case, the Balint group allowed for a secure place for emotional reflection on the leaving process for Dr A and her peers. The patients' various reactions to Dr A's leaving showed that patients and their doctors are attached through subtle, usually unspoken threads. ${ }^{8}$

To read or post commentaries in response to this article, see it online at http://www.annfammed.org/content/9/6/549.
Key words: Physician-patient relations; continuity of patient care; Balint group; group process; separation anxiety; object attachment.

Submitted November 9, 2010; submitted, revised, May 7, 2011; accepted June 8, 2011.

\section{References}

1. Balint M. The Doctor, His Patient, and the Illness. Revised 2nd ed. London: Pitman Paperback; 1968.

2. Lichtenstein A. Integrating intuition and reasoning-how Balint groups can help medical decision making. Austr Fam Phys. 2008; 35(12):987-989.

3. Stokes T, Tarrant C, Mainous AG III, Schers H, Freeman G, Baker R. Continuity of care: is the personal doctor still important? A survey of general practitioners and family physicians in England and Wales, the United States and the Netherlands. Ann Fam Med. 2005;3(4):353-359.

4. Saultz JW, Albedaiwi W. Interpersonal continuity of care and patient satisfaction: a critical review. Ann Fam Med. 2004;(2):445-451.

5. Maoz B, Rabin S, Katz H, Matalon A. The Patient, the Doctor and Their Interactions. 2nd ed. Tel Aviv, Israel: Tel Aviv University; 2004 [Hebrew].

6. Balint E, Norell J. Six Minutes for the Patient: Interaction in General Practice Consultations. London: Tavistock; 1983.

7. Budow M. Chronic constipation and the "flash technique". In: Proceedings of the 16th International Balint Congress. Brasov, Romania: International Balint Congress; 2009.

8. Elder A. The GP surgery as a secure base? Patterns of attachment in primary care. Psychodynamic Pract. 2009;15(1):57-70.

\section{CORRECTION}

Ann Fam Med. 2011;9:551. doi:10.1370/afm.1342.

Mazzone M, Abercrombie S, Gravel J Jr, et al: The Delta-Exchange. Ann Fam Med. 2011;9(5):467-468.

In the 2011 September/October issue of the Annals, the Family Medicine Update from by the Association of Family Medicine Residency Directors contained an incorrect URL for the Data-Exchange Web site. The correct address is http://www.delta-exchange.net. 